\title{
Cytomegalovirus, Epstein-Barr virus and varicella zoster virus infection in the first two years of life: a cohort study in Bradford, UK
}

\author{
Lucy Pembrey ${ }^{1 *}$ D, Dagmar Waiblinger ${ }^{2}$, Paul Griffiths ${ }^{3}$, Mauli Patel $^{4}$, Rafaq Azad ${ }^{5}$ and John Wright ${ }^{2}$
}

\begin{abstract}
Background: Cytomegalovirus (CMV), Epstein Barr virus (EBV) and varicella-zoster virus (VZV) are common herpesviruses frequently acquired in childhood, which establish persistent, latent infection and are likely to impact the developing immune system. Little is known about the epidemiology of CMV and EBV infections in contemporary UK paediatric populations, particularly whether age at infection differs by ethnic group.

Methods: Children enrolled in the Born in Bradford Allergy and Infection Study had a blood sample taken and a questionnaire completed at 12 and 24 months of age. Ordered logistic regression quantified associations between ethnicity and other risk factors and age at CMV/EBVNZV infection ( $<12$ months, 12-24 months, uninfected at 24 months).

Results: Pakistani children $(n=472)$ were more likely to be infected with CMV and EBV at a younger age than White British children ( $n=391$ ) (CMV: adjusted odds ratio (OR) 2.53, 95\% confidence interval (Cl) 1.47-4.33; EBV: adjusted OR 2.16, 95\% Cl 1.43-3.26). Conversely, Pakistani children had lower odds of being VZV infected in the second year than White British children (adjusted OR 0.57, 95\% Cl 0.33-0.97). There was a strong association between increasing birth order and later CMV infection in Pakistani children.

Conclusions: We report large differences in CMV and EBV incidence in the first 2 years between Pakistani and White British children born in Bradford, which cannot be explained by differences in risk factors for infection. Our data will inform the optimum schedule for future CMV and EBV vaccination programmes.
\end{abstract}

Keywords: Cytomegalovirus, Epstein Barr virus, Varicella zoster virus, Children, Ethnic group, UK

\section{Background}

Cytomegalovirus (CMV), Epstein Barr virus (EBV) and varicella-zoster virus (VZV) are common herpesviruses frequently acquired in childhood. They establish persistent, latent infection and are likely to impact the developing immune system [1, 2]. In childhood, VZV causes chickenpox but CMV and EBV infections are usually asymptomatic. If acquired in adolescence, EBV can cause glandular fever. EBV has been associated with immune disorders such as multiple sclerosis and lymphoma $[3,4]$

\footnotetext{
* Correspondence: Lucy.Pembrey@lshtm.ac.uk

'Department of Medical Statistics, London School of Hygiene and Tropical

Medicine, Keppel Street, London WC1E 7HT, UK

Full list of author information is available at the end of the article
}

and CMV seropositivity is associated with inflammation, atherosclerosis and immunosenescence $[5,6]$.

Chickenpox vaccination is not part of the UK routine childhood vaccination programme but zoster vaccine has been introduced for adults in their 70s to prevent shingles [7], while CMV and EBV vaccines are under development [8-10]. Population-based data on the agespecific prevalence and incidence of these viruses is needed to inform the timing and target groups of potential vaccination programmes. Little is known about the epidemiology of CMV and EBV in contemporary paediatric UK populations, particularly in different ethnic groups. A recent US study identified differences in CMV seroprevalence by ethnic group among children but had 
limited data on other relevant variables such as childcare and breastfeeding [11].

The Allergy and Infection Study is a sub-study of the Born in Bradford birth cohort and aims to describe the maternal and paediatric epidemiology of CMV, EBV and VZV infection and to investigate the effect of age at infection on immune function and atopic allergy. The specific objectives of this paper are to estimate the incidence of CMV, EBV and VZV infection at age 1 and 2 years and to identify factors associated with infection, in particular to quantify any differences in age at infection by ethnic group.

\section{Methods}

Children enrolled in the Born in Bradford cohort who were born on or after 1 March 2008 with a maternal baseline questionnaire available were eligible for the Allergy and Infection Study (ALL IN). Details of the Born in Bradford (BiB) cohort are described elsewhere [12]. Briefly, BiB is a multi-ethnic birth cohort study aiming to examine the impact of environmental, psychological and genetic factors on maternal and child health. Bradford is a city in the North of England with high levels of socioeconomic deprivation and ethnic diversity.

Mothers were invited to participate in ALL IN 1 month before their child's first birthday. A questionnaire was completed by those who consented and a $5 \mathrm{ml}$ venous blood sample was taken from the child, centrifuged and stored at $-80{ }^{\circ} \mathrm{C}$. This was repeated 1 year later to provide exposure data and serum at 12 and 24 months. See Additional file 1 for further details.

A sample of 1000 children was selected for serological testing (see Additional file 1 for sample size calculations); 700 based on having 4 or 5 aliquots of the 24month sample and having received the relevant immunisations (for a separate analysis of response to routine vaccination) and 300 randomly selected from those with fewer than 4 aliquots.

At the Royal Free Virology laboratory, the 24-month samples were tested first for CMV-immunoglobulin G (IgG), EBV-IgG and VZV-IgG. If positive, the 12-month sample was tested in the same way. CMV-IgG was tested using the Abbott Architect assay (kit product no. 6c15-25) and EBV-IgG and VZV-IgG using the Diasorin Liaison assays (kit product numbers 310510 and 310850, respectively) [13]. For children who were CMV-IgG positive at 12 months, the cord blood sample was tested for CMVdeoxyribonucleic acid (DNA) using a quantitative realtime polymerase chain reaction method described in detail elsewhere [14]. To verify the expected loss of maternal antibody by 12 months so that IgG testing at this age can represent paediatric infection, a random sample of 100 children who were IgG negative at 24 months for each infection were tested for IgG at 12 months.

\section{Data management and key variables}

Data from several sources were combined: the maternal baseline questionnaire for the main $\mathrm{BiB}$ study, the maternity database (eClipse), the ALL IN questionnaire datasets (12- and 24-month) and the serology results.

Outcome variable: For each of the three infections, IgG results at 12 and 24 months were combined to create an age at infection variable for each child with three categories: infected by 12 months, infected between 12 and 24 months and uninfected at 24 months.

Explanatory variables: The main exposure of interest is ethnicity, defined as mother's ethnic group and cultural background self-reported at the baseline interview during pregnancy, in three categories: White British, Pakistani and Other. Potential confounders are factors which influence exposure to infection via contact with the mother, siblings and others, especially children: birth order [15], breastfeeding [16, 17], household size/composition [15], childcare [18, 19], bedroom sharing [20, 21] and attendance at mother/baby activities [20]. We also considered socio-economic indicators (maternal education, home ownership) which may act as proxies for exposure to infection [11,22].

Parents were asked for details of all regular childcare arrangements, defined as at least $5 \mathrm{~h}$ per week for a duration of at least 1 month. The hours at each childcare arrangement were calculated by: number of months attending the childcare arrangement (age $12 \mathrm{~m}$ questionnaire completed minus age started arrangement) $\mathrm{x}$ hours per week $\mathrm{x} 4.35 \mathrm{x}$ weight for number of other children. The child-hours at each arrangement were added to obtain the total child care hours for each child. This was adapted from the method first used by Ma et al. [19]. Total child care hours were calculated separately for informal (looked after by family members/friends) and formal (childminder/nursery) arrangements. Data collected on breastfeeding at the 12- and 24-month visits were combined to create an ever/never breastfed variable and a breastfeeding duration variable.

Data on several variables were collected at more than one time point. Decisions were made a priori about which to include as follows: CMV-as most infections were acquired in the first year and the greatest difference between ethnic groups is in the first 12 months, childcare up to the 12-month visit was used, total number of members of household at baseline questionnaire was used rather than at 12-month visit, and the summary bedroom sharing variable used referred to the first 12 months. EBV-although there were differences by ethnic group in the first 12 months and from 12 to 24 months, most infections were acquired between 12 and 24 months. Household size and number of children in the household collected at the 12-month visit were used rather than the baseline questionnaire data, and 
bedroom sharing from 12 months collected at the 24month visit was included. VZV-the difference between ethnic groups is at $12-24$ months so the same variables were used as for the EBV analysis.

\section{Statistical methods}

All data analysis was conducted using Stata version 13 [23].

To quantify the associations between age at $\mathrm{CMV} /$ EBV/VZV infection and risk factors for infection, ordered logistic regression was used, excluding 137 children who were not White British or Pakistani to focus the comparison between the two main groups. The resulting odds ratios are for infection by 12 months compared to infection between 12 and 24 months and infection between 12 and 24 months compared to uninfected at 24 months, i.e. the odds ratio compares each category with the next and the steps between categories are assumed to be equal. This proportional odds assumption was checked for each of the variables included. For the unstratified multivariable model of age at VZV infection, multinomial logistic regression was used as the proportional odds assumption was not satisfied.

First, multivariable models quantified the difference in age at infection between White British and Pakistani children, adjusting for other risk factors for infection. Due to differences in the prevalence of potential risk factors for infection between the White British and Pakistani children, analyses were then stratified by ethnic group to identify the most important risk factors in each group.

Most variables were included $a$ priori as factors which influence exposure to infection. As some variables were likely to be highly correlated (e.g. birth order and number of children in household), likelihood ratio tests determined which of each pair should be retained in the model. Socio-economic factors were then added to the model and retained if the univariable $p$ value was $<0.05$ or the likelihood ratio test $p$ value for inclusion in the multivariable model was $<0.05$. Maternal age was included a priori in the CMV models as a proxy for maternal serostatus (CMV seropositivity increases with age). The timing of blood collection visits varied around 12 and 24 months of age; as the chance of a seropositive result would increase with age, the actual age at the planned 24-month blood sample variable was included in multivariable models.

\section{Results}

Of 7423 eligible children, the parents of 5891 were contacted and invited to take part in ALL IN and 3196 (54\%) agreed. Of the 2695 parents who declined, 2013 gave a reason: 1075 (53\%) not happy about having blood samples taken, 510 (25\%) too busy and 428 (21\%) gave other reasons. Figure 1 shows the number of children completing a 12- and 24-month visit. The children recruited were born between March 2008 and June 2011.
Of the 24-month samples, there were 5 equivocal results for VZV which were considered negative. One-third of children (323) were seronegative for all three infections and 677 seropositive for at least one. A 12-month sample was not available for 58 of 677 children so 12 -month samples for 619 children were tested. 231 children were CMV-IgG positive at 12 months. Cord blood was available for 154 of these; one child had detectable CMV-DNA (52,268 CMV VL genomes/ml) while 153 were undetectable $(<200$ copies $/ \mathrm{ml})$. Testing to verify loss of maternal antibody gave the following results: For EBV none of the 101 children who were IgG negative at 24 months were IgG positive at 12 months. For CMV two of 103 children, and for VZV two of 101 children, who were IgG negative at 24 months were IgG positive at 12 months (with the same results on re-testing).

This analysis includes 1000 children with CMV, EBV and VZV infection status at 12 and 24 months. 391 (39\%) children were born to White British women, 472 (47\%) to Pakistani women and $137(14 \%)$ to women of other ethnic groups (Table 1). Table 1 shows the characteristics of the children and their mothers by ethnic group (also see Additional file 2).

The 1000 children selected for this analysis were similar to the ALL IN children who were not included with respect to ethnic group, mother's country of birth, sex, childcare, household size and number of children in the household but were more likely to have been breastfed ( $81 \%$ vs. $74 \%$ ). Compared to the rest of the $\mathrm{BiB}$ cohort (12,538 children), the 1000 ALL IN children were similar in terms of most characteristics but their mothers were slightly more likely to be married and living with partner ( $72 \%$ vs. $65 \%)$ and to be in the least deprived quintiles of the Index of Multiple Deprivation.

There were marked differences in the incidence of CMV and EBV infection at 12 and 24 months between the White British and Pakistani children with the Pakistani children infected earlier (Fig. 2 and Additional file 3).

\section{CMV}

One-third of Pakistani children (162, 34\%) were infected by 12 months compared to $9 \%$ (36) of White British children, with a further $10 \%(47)$ and $6 \%(25)$ respectively infected between 12 and 24 months. In unadjusted analysis there was a 4-fold increase in odds of being infected by 12 months than between 12 and 24 months or infected between 12 and 24 months than uninfected at 24 months in Pakistani children compared to White British children (odds ratio (OR) 4.44, 95\% confidence interval (CI) 3.20-6.14, <0.001). This association attenuated with adjustment for covariates (birth order, household size, breastfeeding duration, bedroom sharing, childcare, mother/baby activities, travel outside Europe, maternal age, mother's country 


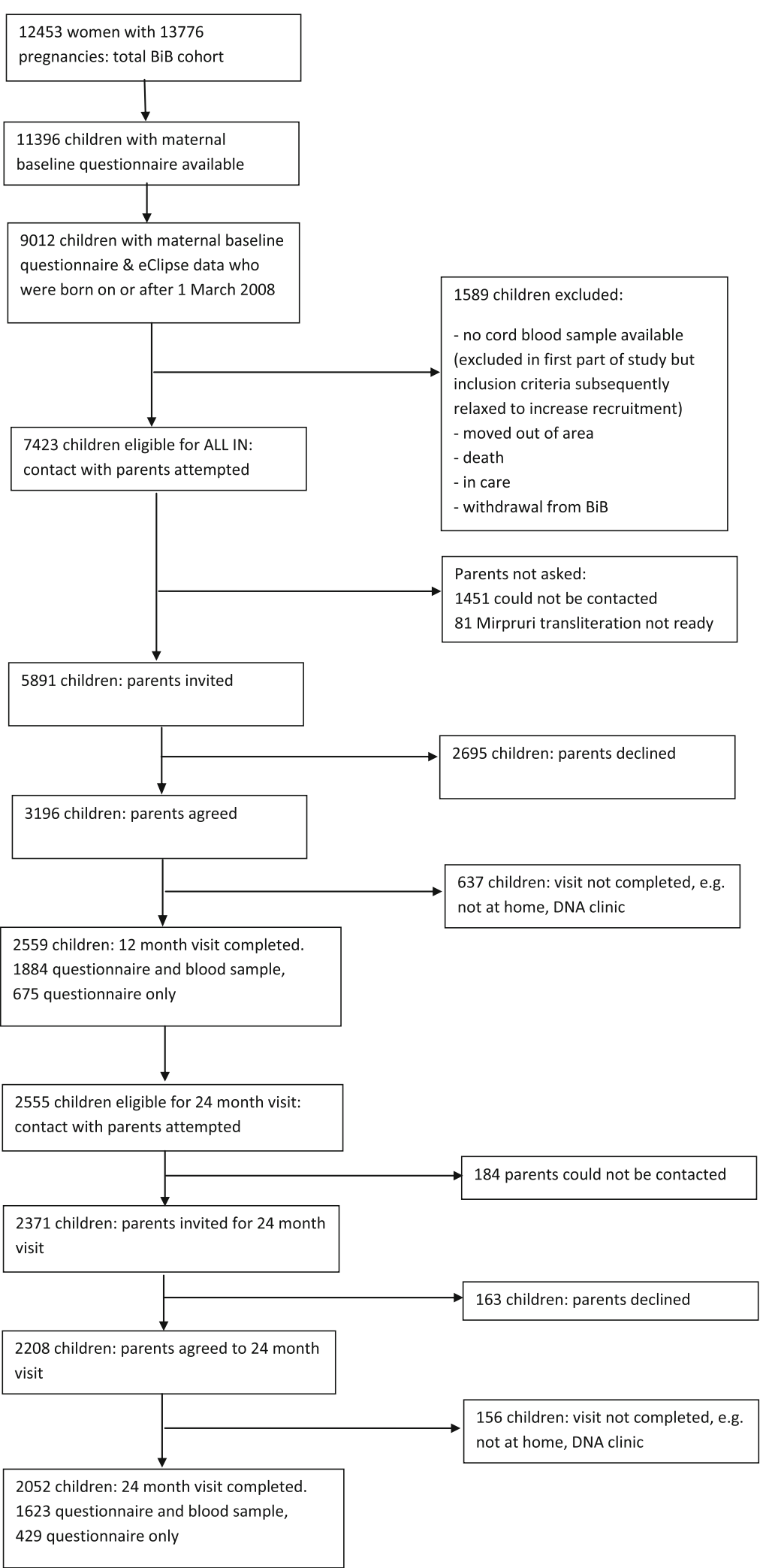

Fig. 1 Children included in the Born in Bradford Allergy and Infection Study 
Table 1 Characteristics of the children and their mothers

\begin{tabular}{|c|c|c|c|}
\hline & All $(n=1000)$ & White British $(n=391)$ & Pakistani $(n=472)$ \\
\hline \multicolumn{4}{|l|}{ Mother's baseline questionnaire } \\
\hline \multicolumn{4}{|l|}{ Mother's ethnic group } \\
\hline White British & 391 (39\%) & & \\
\hline White Other & $26(3 \%)$ & & \\
\hline Mixed-White and Black & $8(1 \%)$ & & \\
\hline Mixed-White and South Asian & $5(1 \%)$ & & \\
\hline Black & $17(2 \%)$ & & \\
\hline Indian & $42(4 \%)$ & & \\
\hline Pakistani & $472(47 \%)$ & & \\
\hline Bangladeshi & $15(1 \%)$ & & \\
\hline Other & $24(2 \%)$ & & \\
\hline \multicolumn{4}{|l|}{ Mother's country of birth } \\
\hline UK \& Ireland & $612(61 \%)$ & 386 (99\%) & 177 (38\%) \\
\hline Elsewhere & $388(39 \%)$ & $5(1 \%)$ & $295(62 \%)$ \\
\hline $\begin{array}{l}\text { Mother's age at recruitment (yrs) } \\
\text { mean, SD, range }\end{array}$ & $28.9,5.57,15-44$ & $28.9,5.96,15-43$ & $28.8,5.28,17-44$ \\
\hline \multicolumn{4}{|l|}{ Marital \& cohabitation status combined } \\
\hline Married and living with partner & $716(72 \%)$ & $167(43 \%)$ & 445 (94\%) \\
\hline Not married and living with partner & $170(17 \%)$ & $146(37 \%)$ & 1 \\
\hline Not living with partner & $113(11 \%)$ & $77(20 \%)$ & $26(6 \%)$ \\
\hline missing (married, cohab status missing) & 1 & 1 & 0 \\
\hline \multicolumn{4}{|l|}{ Birth order } \\
\hline 1 & 367 (37\%) & $184(47 \%)$ & $126(27 \%)$ \\
\hline 2 & $289(29 \%)$ & $128(33 \%)$ & $107(23 \%)$ \\
\hline $3-4$ & $290(29 \%)$ & $72(18 \%)$ & $194(41 \%)$ \\
\hline $5+$ & $54(5 \%)$ & $7(2 \%)$ & $45(9 \%)$ \\
\hline \multicolumn{4}{|l|}{ Total no. of household members } \\
\hline median, IQR, range & $4,3-5,1-16$ & $3,2-3,1-8$ & $5,4-7,2-16$ \\
\hline missing & 1 & 1 & 0 \\
\hline \multicolumn{4}{|l|}{ No. of household members under 16 years } \\
\hline median, IQR, range & $1,0-2,0-7$ & $1,0-1,0-6$ & $2,1-3,0-7$ \\
\hline missing & 1 & 1 & 0 \\
\hline \multicolumn{4}{|c|}{ Mother's highest educational qualification (equivalised) } \\
\hline$<5$ GCSE equivalent & $200(20 \%)$ & $59(15 \%)$ & $130(28 \%)$ \\
\hline 5 GCSE equivalent & $253(25 \%)$ & $98(25 \%)$ & $135(29 \%)$ \\
\hline A level equivalent & 147 (15\%) & $72(18 \%)$ & $55(12 \%)$ \\
\hline higher than A level & $313(31 \%)$ & $118(30 \%)$ & $134(28 \%)$ \\
\hline Other/don't know/foreign unknown & $86(9 \%)$ & $44(11 \%)$ & $17(3 \%)$ \\
\hline missing & 1 & 0 & 1 \\
\hline \multicolumn{4}{|l|}{ Mother's employment status } \\
\hline Currently employed & $461(46 \%)$ & $279(71 \%)$ & $94(20 \%)$ \\
\hline Previously employed & $238(24 \%)$ & $91(23 \%)$ & 117 (25\%) \\
\hline Never employed & $300(30 \%)$ & $21(5 \%)$ & $261(55 \%)$ \\
\hline missing & 1 & & \\
\hline
\end{tabular}


Table 1 Characteristics of the children and their mothers (Continued)

\begin{tabular}{|c|c|c|c|}
\hline \multicolumn{4}{|l|}{ Father's employment status } \\
\hline Employed non-manual & $414(44 \%)$ & $215(59 \%)$ & 135 (30\%) \\
\hline Employed manual & $298(31 \%)$ & $85(23 \%)$ & $172(38 \%)$ \\
\hline Self-employed & $166(17 \%)$ & $38(10 \%)$ & $111(25 \%)$ \\
\hline Student & $9(1 \%)$ & $4(1 \%)$ & 2 \\
\hline Unemployed & $54(6 \%)$ & $21(6 \%)$ & $28(6 \%)$ \\
\hline Don't know & $5(1 \%)$ & $4(1 \%)$ & 1 \\
\hline missing & 54 & 24 & 23 \\
\hline \multicolumn{4}{|c|}{ Mother smoked during pregnancy } \\
\hline Yes & $135(14 \%)$ & $110(28 \%)$ & $15(3 \%)$ \\
\hline No & $863(86 \%)$ & $281(72 \%)$ & $456(97 \%)$ \\
\hline missing & 2 & & 1 \\
\hline \multicolumn{4}{|c|}{ Index of Multiple Deprivation (IMD) 2010 quintile (national) } \\
\hline 1 (most deprived) & $640(64 \%)$ & $162(41 \%)$ & $387(82 \%)$ \\
\hline 2 & $164(16 \%)$ & $87(22 \%)$ & $49(10 \%)$ \\
\hline 3 & $141(14 \%)$ & $94(24 \%)$ & $30(6 \%)$ \\
\hline 4 & $35(4 \%)$ & $31(8 \%)$ & $4(1 \%)$ \\
\hline 5 (least deprived) & $20(2 \%)$ & $17(4 \%)$ & 2 \\
\hline \multicolumn{4}{|l|}{ Maternity records } \\
\hline $\begin{array}{l}\text { Parity (registerable) } \\
\text { median, IQR, range }\end{array}$ & $1,0-2,0-7$ & $1,0-1,0-6$ & $2,0-3,0-7$ \\
\hline missing & 26 & 10 & 14 \\
\hline $\begin{array}{l}\text { Gestational age (to last } \\
\text { median, IQR, range }\end{array}$ & $39,38-40,29-44$ & $40,38-40,29-44$ & $39,38-40,20-42$ \\
\hline missing & 6 & 2 & 3 \\
\hline $\begin{array}{l}\text { Birth weight (g) } \\
\text { median, IQR, range }\end{array}$ & $\begin{array}{l}3280,2920-3610 \\
890-4904\end{array}$ & $\begin{array}{l}3400,3050-3710 \\
890-4820\end{array}$ & $\begin{array}{l}3180,2880-3490 \\
1275-4520\end{array}$ \\
\hline missing & 6 & 2 & 3 \\
\hline \multicolumn{4}{|l|}{ Route of birth } \\
\hline vaginal & 783 (79\%) & $296(76 \%)$ & 387 (83\%) \\
\hline caesarean & $211(21 \%)$ & $93(24 \%)$ & $82(17 \%)$ \\
\hline missing & 6 & 2 & 3 \\
\hline \multicolumn{4}{|l|}{ Sex of baby } \\
\hline Male & $531(53 \%)$ & 190 (49\%) & $262(55 \%)$ \\
\hline Female & $469(47 \%)$ & $201(51 \%)$ & $210(44 \%)$ \\
\hline \multicolumn{4}{|l|}{ ALL IN questionnaires } \\
\hline Ever breastfed & $806(81 \%)$ & $289(74 \%)$ & $386(82 \%)$ \\
\hline Never breastfed & 192 (19\%) & $102(26 \%)$ & $84(18 \%)$ \\
\hline missing & 2 & 0 & 2 \\
\hline \multicolumn{4}{|l|}{ Duration of breastfeeding } \\
\hline never & $192(19 \%)$ & $102(26 \%)$ & $84(18 \%)$ \\
\hline$<=4$ weeks & $210(21 \%)$ & 99 (25\%) & $91(19 \%)$ \\
\hline $1-6$ months & $243(24 \%)$ & 95 (24\%) & $121(26 \%)$ \\
\hline $6-12$ months & 219 (22\%) & 65 (17\%) & 102 (22\%) \\
\hline
\end{tabular}


Table 1 Characteristics of the children and their mothers (Continued)

\begin{tabular}{|c|c|c|c|}
\hline$>12$ months & $131(13 \%)$ & $29(7 \%)$ & $70(15 \%)$ \\
\hline missing & 5 & 1 & 4 \\
\hline \multicolumn{4}{|l|}{ Bedroom/bed sharing } \\
\hline Shared bedroom up to 6 mths: Yes & $912(92 \%)$ & $323(83 \%)$ & $463(99 \%)$ \\
\hline No & 82 & 66 & 5 \\
\hline missing & 6 & 2 & 4 \\
\hline Shared bedroom from 6 mths to $12 \mathrm{mth}$ visit: Yes & $716(72 \%)$ & $170(44 \%)$ & $439(94 \%)$ \\
\hline No & 278 & 219 & 29 \\
\hline missing & 6 & 2 & 4 \\
\hline Shared bedroom from 12 mths: Yes & $688(69 \%)$ & $143(37 \%)$ & $448(95 \%)$ \\
\hline No & 312 & 248 & 24 \\
\hline Shared bed from 12 mths: Yes & $273(27 \%)$ & $27(7 \%)$ & $204(43 \%)$ \\
\hline No & 726 & 364 & 267 \\
\hline missing & 1 & & 1 \\
\hline \multicolumn{4}{|l|}{ Childcare } \\
\hline Ever regular childcare by $12 \mathrm{~m}$ visit & $348(35 \%)$ & $228(58 \%)$ & $63(13 \%)$ \\
\hline Never regular childcare by $12 \mathrm{~m}$ & 646 & 161 & 405 \\
\hline missing & 6 & 2 & 4 \\
\hline Ever regular childcare by $24 \mathrm{~m}$ visit & $426(43 \%)$ & $266(68 \%)$ & $92(19 \%)$ \\
\hline Never regular childcare by $24 \mathrm{~m}$ & $574(57 \%)$ & $125(32 \%)$ & $380(81 \%)$ \\
\hline \multicolumn{4}{|l|}{ Mother \& baby activities up to $6 \mathrm{~m}$} \\
\hline Rarely & $634(64 \%)$ & 169 (44\%) & $383(82 \%)$ \\
\hline At least once a month & $41(4 \%)$ & $24(6 \%)$ & $11(2 \%)$ \\
\hline Usually once a week & $191(19 \%)$ & $104(27 \%)$ & $55(12 \%)$ \\
\hline More than once a week & $126(13 \%)$ & $91(23 \%)$ & $18(4 \%)$ \\
\hline missing & 8 & 3 & 5 \\
\hline \multicolumn{4}{|l|}{ Mother \& baby activities $6 \mathrm{~m}$ to $12 \mathrm{~m}$ visit } \\
\hline Rarely & $593(60 \%)$ & $175(45 \%)$ & $337(72 \%)$ \\
\hline At least once a month & $66(7 \%)$ & $32(8 \%)$ & $26(6 \%)$ \\
\hline Usually once a week & $203(20 \%)$ & $92(24 \%)$ & $79(17 \%)$ \\
\hline More than once a week & $132(13 \%)$ & $90(23 \%)$ & $26(5 \%)$ \\
\hline missing & 6 & 2 & 4 \\
\hline \multicolumn{4}{|l|}{ Ever travelled outside UK up to $12 \mathrm{~m}$ visit } \\
\hline No & $773(78 \%)$ & $320(82 \%)$ & $373(79 \%)$ \\
\hline Within Europe & $93(9 \%)$ & $61(16 \%)$ & $4(1 \%)$ \\
\hline Outside Europe & $128(13 \%)$ & $7(2 \%)$ & $92(20 \%)$ \\
\hline missing & 6 & 3 & 3 \\
\hline \multicolumn{4}{|l|}{ Travelled outside UK since 1st birthday (up to 24 m visit) } \\
\hline No & $686(69 \%)$ & $271(69 \%)$ & $343(73 \%)$ \\
\hline Within Europe & $155(15 \%)$ & $110(28 \%)$ & $12(2 \%)$ \\
\hline Outside Europe & 159 (16\%) & $10(3 \%)$ & $117(25 \%)$ \\
\hline
\end{tabular}




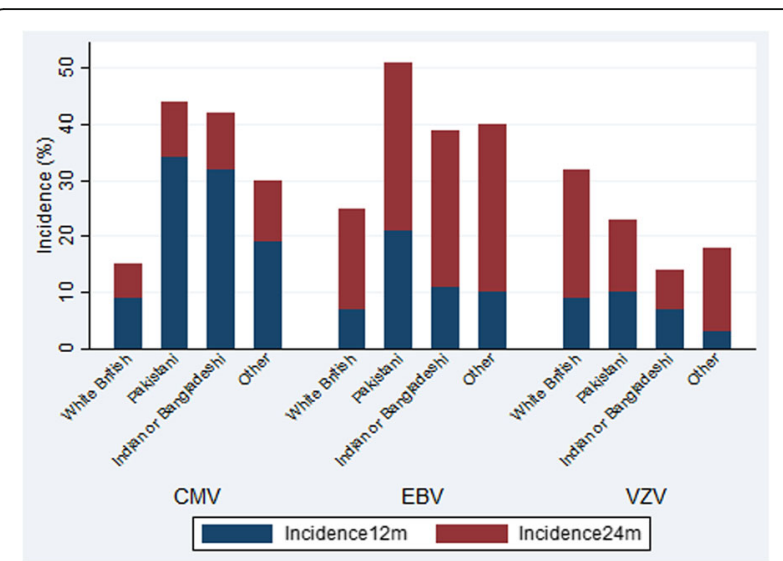

Fig. 2 Incidence of CMV, EBV and VZV infection at 12 and 24 months by ethnic group

of birth, home ownership and age blood sample taken) but there remained strong evidence of a 2.5 -fold increase in odds of earlier infection among Pakistani children compared to White British children (adjusted OR $=2.53$, 95\% CI 1.47-4.33, $p=0.001$ ).

Maternal infection status was only available for 90 children; 71/90 (79\%) mothers were CMV seropositive (52\% (17/33) of White British and 94\% (48/51) of Pakistani women). Among the children of seropositive mothers, 3/ 17 (18\%) White British children were infected by 12 months compared to $14 / 48$ (29\%) Pakistani children. An adjusted sub-group analysis was not possible due to small numbers in some groups but the pattern of earlier infection among Pakistani children remains.

To identify the most important risk factors in each group, the adjusted analysis was run separately for White British and Pakistani children (Table 2). The key associations are summarised in Table 5. Of particular note, among the Pakistani children increasing duration of breastfeeding was strongly associated with earlier infection whereas among White British children earlier infection was only evident for those breastfed for 6 months or more. There was a strong association between increasing birth order and later age at infection in the Pakistani children such that children with one or more older siblings had $60 \%$ lower odds of being infected by 12 months or between 12 and 24 months than first-born children. The birth order estimates for White British children were in the same direction but no statistically significant association was observed.

\section{EBV}

7\% (28) of White British children were infected by 12 months compared to $21 \%$ (101) of Pakistani children and a further 18\% (71) and 30\% (140) respectively were infected between 12 and 24 months. In unadjusted ordered logistic regression analysis, Pakistani children had three times the odds of being EBV infected by 12 months than between 12 and 24 months or between 12 and 24 months than to remain uninfected at 24 months than the White British children (OR 3.14, 95\% CI 2.36-4.18, $p<0.001)$. When adjusting for birth order, household size at 12 months, bedroom sharing in the first year, breastfeeding duration, formal childcare hours in the first and second years, mother/baby activities in the first year, travel outside Europe since first birthday, maternal age, maternal education and age blood sample taken, Pakistani children had twice the odds of being infected earlier than White British children (adjusted OR 2.16, 95\% CI 1.43-3.26, $p<0.001)$.

The analysis was stratified by ethnic group (Table 3), with key associations summarised in Table 5. The unexpected strong association between later infection and mother/baby activities is limited to White British children who had ever attended childcare and relates to attendance between 6 and 12 months (rather than $<6$ months) but there was no clear dose-response relationship with the original 4-category variable. In multivariable analysis among White British children, the odds ratios for the original variable for mother/baby activities between 6 and 12 months were around 0.5 but only one was of (borderline) statistical significance $(p=0.05)$.

\section{VZV}

The incidence of VZV infection at 12 months was similar for Pakistani and White British children (10\% and 9\% respectively) but between 12 and 24 months incidence was higher in the White British children (23\% vs. $14 \%$ in the Pakistani children). In unadjusted multinomial logistic regression analysis, there was no difference in the proportion of children infected by 12 months by ethnic group (OR 1.00, 95\% CI 0.62-1.60) but Pakistani children had nearly $50 \%$ lower odds of being infected between 12 and 24 months than White British children (OR 0.53, 95\% CI 0.37-0.76, $p=0.001$ ). This association remained, although with wider confidence intervals, after adjusting for birth order, household size at 12 months, breastfeeding duration, formal childcare hours in first and second years, bedroom sharing in the second year, mother/baby activities in the second year, maternal age and age blood sample taken: by $12 \mathrm{~m}$ adjusted OR 0.83 , 95\% CI $0.41-1.68, p=0.60 ; 12-24 \mathrm{~m}$ adjusted OR 0.57 , 95\% CI 0.33-0.97, $p=0.04$.

Results of the multivariable ordered logistic regression analysis, stratified by ethnic group, are shown in Table 4. Higher birth order was associated with earlier VZV infection in White British and Pakistani children, with secondborn children having the highest odds of earlier infection. Among the Pakistani children, for every year increase in maternal age there was a $5 \%$ decrease in odds of early VZV infection (Table 4). 


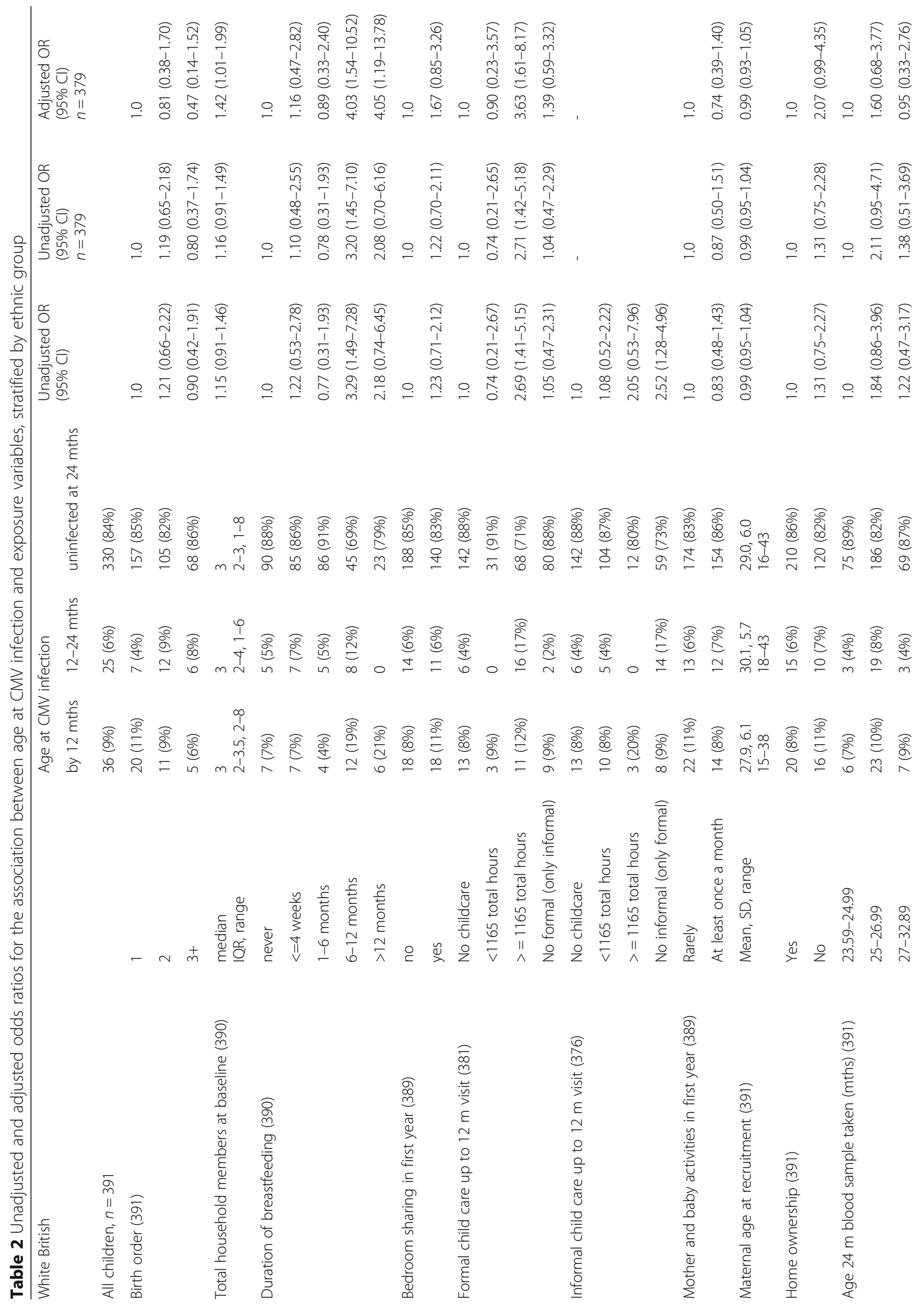




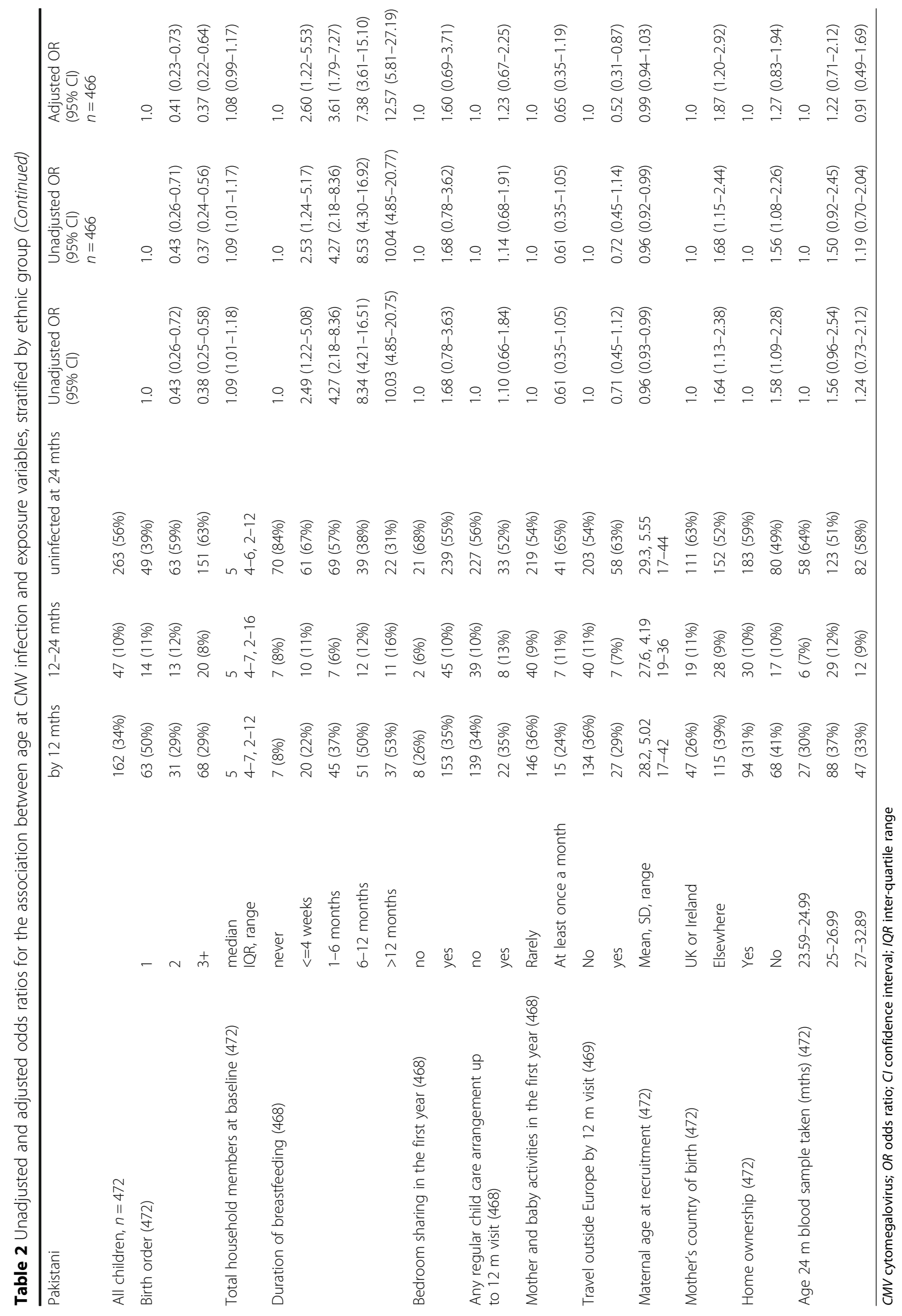




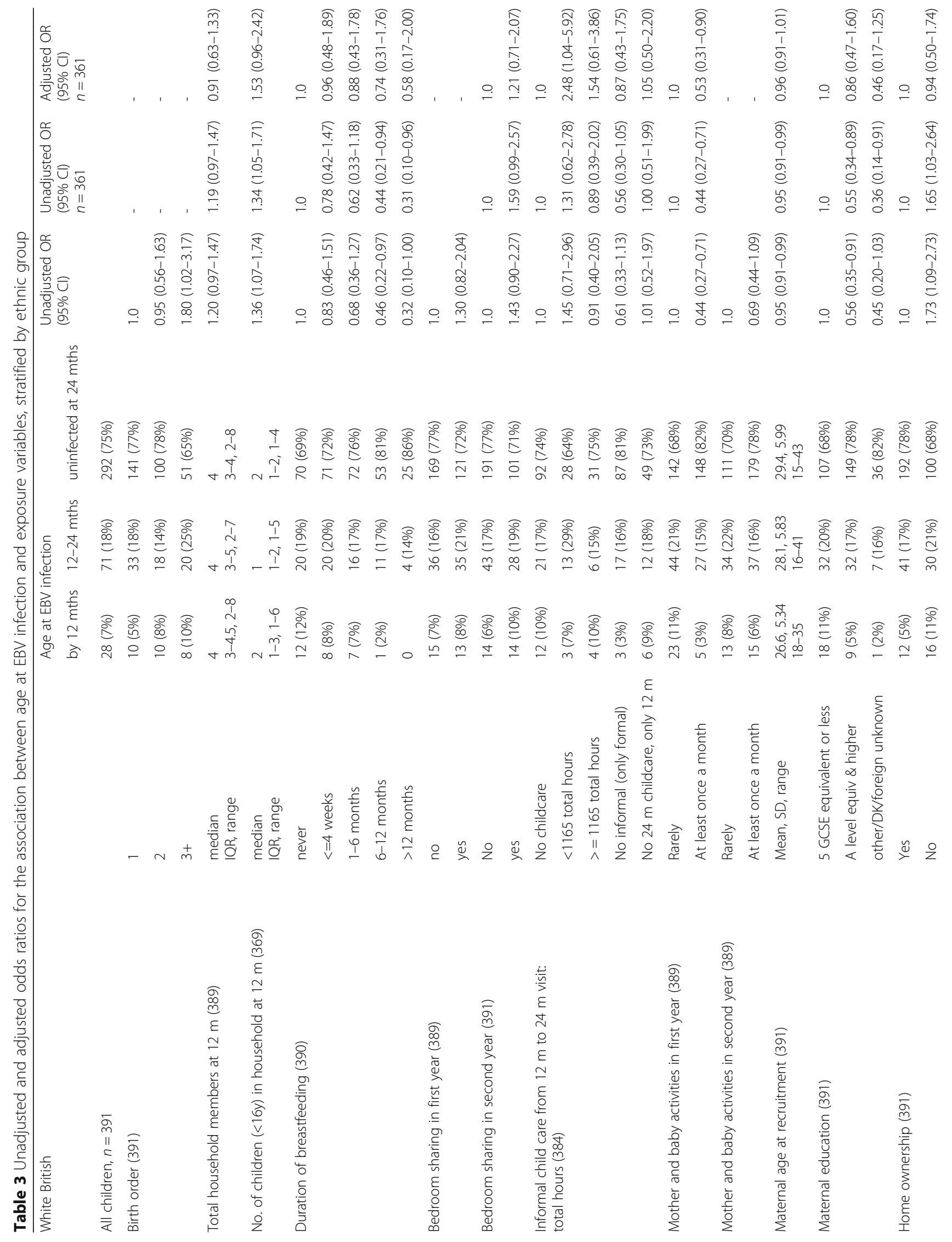




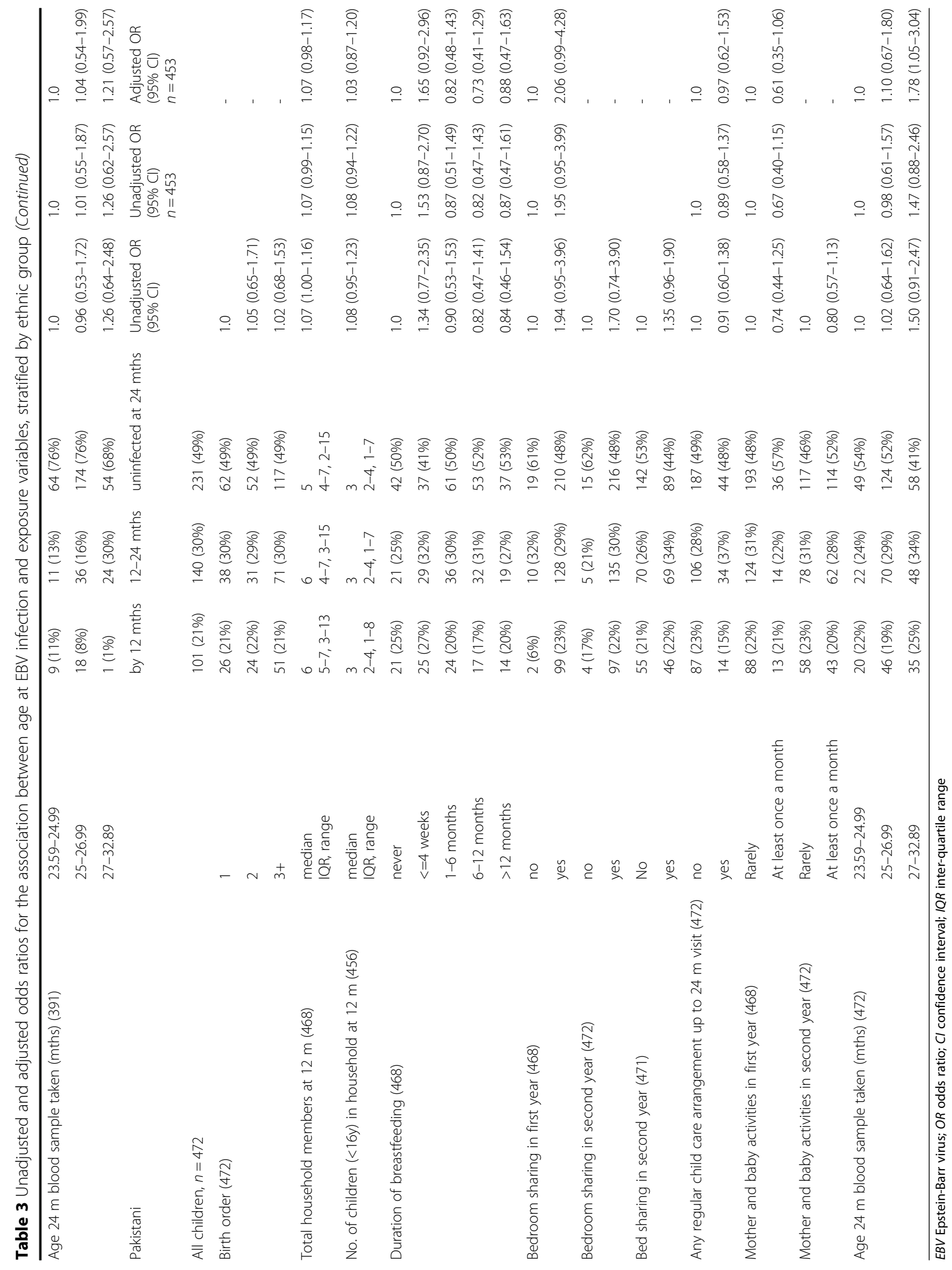




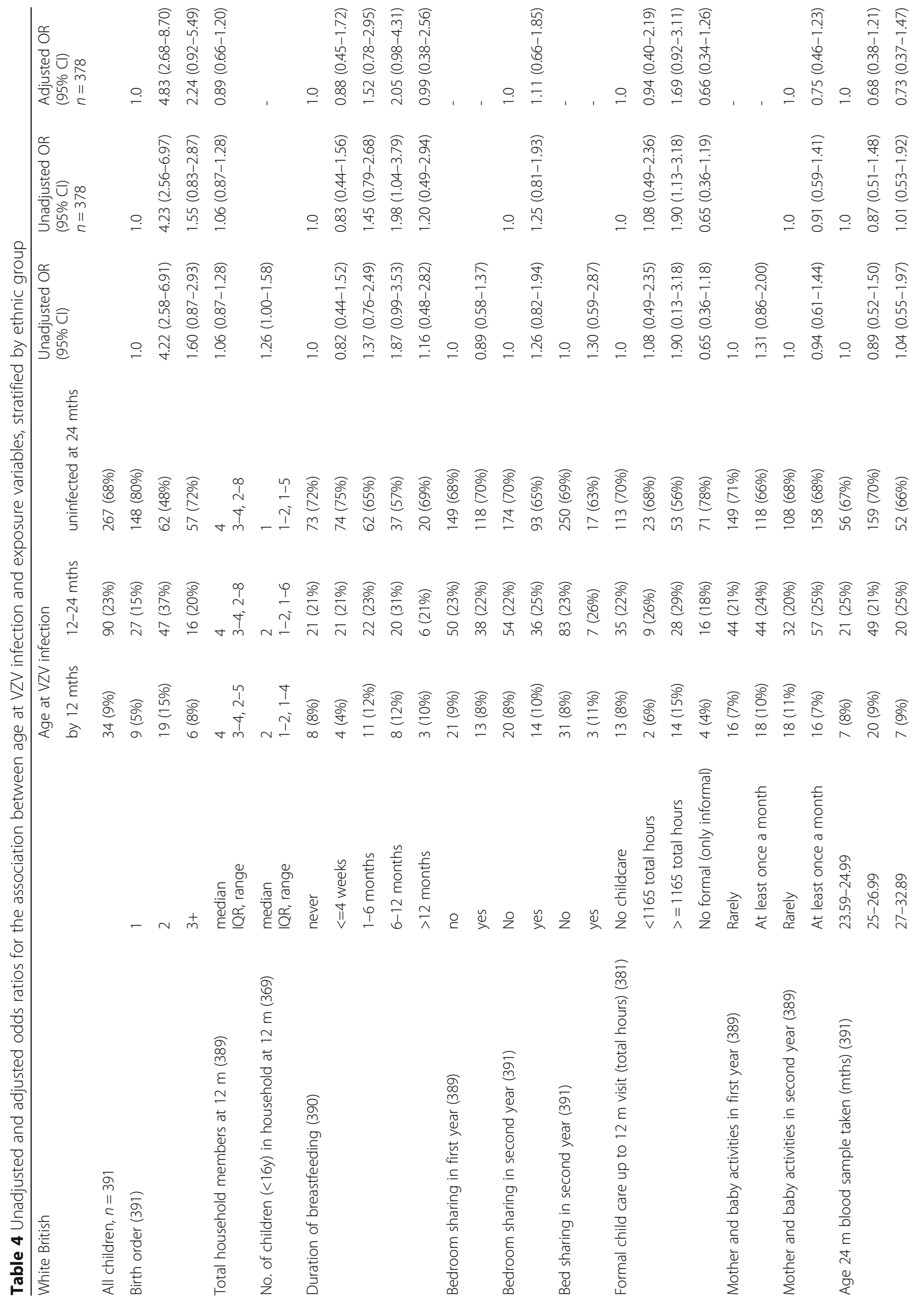




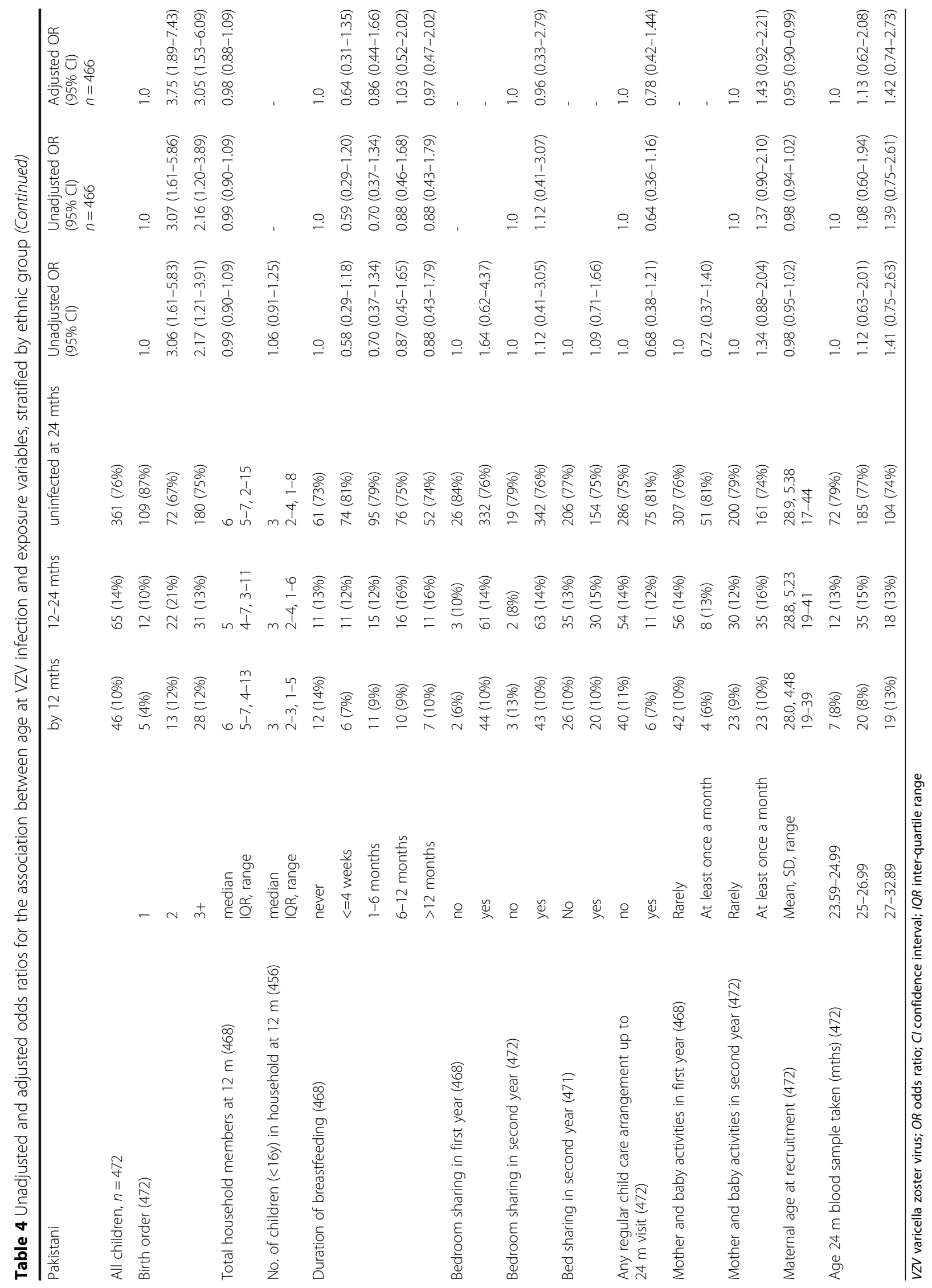




\section{Discussion}

One-third of Pakistani children were CMV infected in the first year compared to $9 \%$ of White British children. By 2 years, half of Pakistani children were EBV infected compared to a quarter of White British children. The higher incidence of CMV and EBV infection among Pakistani children cannot be fully explained by differences in breastfeeding, family size, childcare and socio-economic indicators. VZV incidence from 12 to 24 months was lower among the Pakistani than White British children. Risk factors for CMV and EBV infection differed by ethnic group.

Our VZV estimates are similar to those from previous UK studies [18, 24]. In the Millennium Cohort Study, children from other ethnic groups were less likely to have had chickenpox by age 3 years than white children, based on maternal report, similar to our findings [18]. There is good evidence that VZV seroprevalence in the UK is lower among pregnant women born in Asia than those born in the UK $[13,25]$, due to later age at infection in many tropical countries compared to the UK. However, it is unclear why children born to Asian women in the UK are infected later, as VZV is predominantly transmitted between children rather than from contact with the mother. It has been suggested that infection with CMV affords some cross-protection against VZV [18, 26] which could explain the later VZV infection in Pakistani children in our study as they are infected with CMV earlier than the White British children.

Our CMV incidence results were similar to a crosssectional study in the Netherlands [27]. CMV seroprevalence in 1- and 2-year-olds in a US study was lower than our overall results, although there were small numbers of children in each age group $(<200)$ [11]. The only other UK study on CMV prevalence in young children was based in a London hospital 30 years ago and $20 \%$ of children were infected by 12 months [16]. Results from Australia and Sweden showed slightly higher seroprevalence at 2 years $[28,29]$. Our CMV results on breastfeeding, childcare and socio-economic indicators are consistent with previous findings and we report novel results on birth order (Table 5).
Ethnicity was a key risk factor in several studies with consistent findings of higher CMV prevalence among children in non-white ethnic groups compared to white/ European/Western groups [11, 27, 30]. This association was specifically investigated in relation to other factors in studies in New Zealand [31] and the Netherlands [32] in children aged 3.5 and 6 years, respectively. Differences by ethnic group could not be explained by differences in parity, day care, breastfeeding, and socio-economic indicators, similar to our findings.

The unexpected apparent protective effect of higher birth order on early CMV infection among Pakistani children is unlikely to be spurious for several reasons. First, the birth order effect commonly associated with childhood infections (i.e. children of higher birth order more likely to be infected earlier) was observed for VZV in our study. Second, estimates for the White British children are also less than one although the confidence intervals cross one. Third, Jansen et al. report a similar finding; multiparity was inversely associated with CMV seropositivity by age 6 years (OR 0.76, 95\% CI 0.65-0.90) [32]. The 'birth order effect' is usually discussed in relation to the hygiene hypothesis and refers to the lower risk of atopic disease among children of higher birth order due to increased exposure to childhood infections [15]. An alternative or contributing explanation for this effect could be changes in the maternal immune system with increasing parity so that the effect is determined in the prenatal period [33]. Whether these changes could also affect the maternal immune response to CMV infection and thereby the risk of transmitting virus to her child (e.g. through breastmilk) warrants further investigation. Perhaps CMV infection in the first child acts like a vaccine to boost maternal immunity so she has lower viral load and takes longer to infect subsequent children. Any such effect might be manifest through acquiring immune responses to strains of CMV different from the initial maternal infection, because prototype CMV vaccines can boost the immunity of seropositive adults [8, 34, 35].

Table $\mathbf{5}$ Summary of main associations with age at infection

\begin{tabular}{|c|c|c|c|c|}
\hline & & CMV & EBV & VZV \\
\hline \multirow[t]{2}{*}{ Associated with earlier infection } & White British & $\begin{array}{l}\text { - household size } \\
\text { - breastfeeding }>6 m^{\mathrm{b}}[16,32,42] \\
\text { - formal childcare in } 1 \mathrm{st} \mathrm{yr}^{\mathrm{b}}[32] \\
\text { - not owner-occupied household }{ }^{\mathrm{b}}[11]\end{array}$ & - informal childcare $<1165$ hrs $^{c}$ & - birth order ${ }^{\mathrm{b}}[18]$ \\
\hline & Pakistani & $\begin{array}{l}\text { - } \text { breastfeeding }^{b} \\
\text { - mother born outside UK/Ireland }{ }^{c}\end{array}$ & - bedroom sharing in 1st $\mathrm{yr}^{\mathrm{b}}$ [21] & - birth order ${ }^{b}$ \\
\hline \multirow[t]{2}{*}{ Associated with later infection } & White British & - & - mother/baby activities in 1st $\mathrm{yr}^{\mathrm{a}}$ & - \\
\hline & Pakistani & $\begin{array}{l}\text { - birth order }{ }^{\mathrm{a}} \\
\text { - travel outside Europe in 1st } \mathrm{yr}^{\mathrm{r}^{\mathrm{b}}}\end{array}$ & - & - maternal age ${ }^{a}$ \\
\hline
\end{tabular}

\footnotetext{
${ }^{\text {a novel associations }}$

${ }^{\mathrm{b}}$ previous studies with similar findings (refs)

cexpected association

*assuming this reflects higher socio-economic position
} 
Our EBV incidence estimates are comparable to results from previous UK studies [36-38]. Differences in paediatric EBV prevalence by ethnic group have been reported from two US studies [22, 39] and one in the Netherlands [32]. Socio-economic position and family size partly explained the ethnic differences observed in the Generation R study [32] but the lower prevalence in white children could not be explained by infection risk factors in the Minnesota study [39].

The unexpected association between attendance at mother/baby activities and later EBV infection among White British children may have arisen due to uncontrolled confounding by socio-economic factors; further investigation did not provide convincing evidence of a real effect as the association was only evident in a sub-group.

Ethnic differences in paediatric CMV and EBV incidence have not been reported before in the UK but our results are in line with findings in different populations. As these cannot be fully explained by factors influencing exposure to infection, genetic variation may play a role. For example, the prevalence of the NKG2C deletion is known to vary between populations and is important in NK cell responses to CMV infection such that individuals with the deletion are less able to control CMV viraemia so CMV may be more easily transmitted [40]. Genetic susceptibility may also be important in infectious mononucleosis following EBV infection [41].

A key strength of this study is having serology data at two time points early in childhood. Previous studies have been cross-sectional or with samples available for only one time point. Our results demonstrate that most of the CMV infections occurred in the first year and are generally due to contact with the mother, whereas most EBV and VZV infections are acquired in the second year through contact with siblings and other children. Pinpointing age at infection is important when examining associations with subsequent development of atopic disease $[42,43]$ as there is likely to be a critical window in immune development in the first 2 years during which infection with CMV and/or EBV may influence immune-related outcomes.

We collected detailed information on likely sources of exposure to infection, with few missing values due to interviewer-administered questionnaires with well-trained interviewers. This study had the statistical power to investigate differences in acquisition of infection between two large ethnic groups and the advantages of a prospective birth cohort design with rich characterisation and homogeneity within ethnic groups. There were few differences between the children in this analysis and the main $\mathrm{BiB}$ cohort and our results are generalisable to other multi-ethnic urban UK populations. Our results may not be generalisable to less deprived populations within the UK where the incidence of CMV and EBV infection by age 2 years is likely to be lower than in Bradford.
A limitation of our study is that maternal CMV serostatus was unavailable for most children. Adjustment for mother's country of birth and maternal age would have partially accounted for maternal serostatus as South Asian women born abroad have higher seroprevalence than those born in the UK [13] and seroprevalence increases with age. The pattern of higher incidence at 12 months in Pakistani than White British children was still evident in the sub-group of CMV seropositive women.

Misclassification of age at CMV and VZV infection due to the occasional presence of maternal antibody at 12 months is likely to have had a minimal effect; the adjusted incidence figures rounded to the same percentage points.

\section{Conclusions}

This study provides current incidence data for three common herpesviruses in young children which are generalisable to urban UK populations. We have demonstrated large differences in incidence between White British and Pakistani children for the first time in the UK and have identified key risk factors for infection in each group, some novel, which suggest mechanisms of transmission to be investigated further.

Our data will inform the optimum schedule of potential CMV and EBV vaccination programmes. For CMV it has been proposed that toddlers as well as adolescents are vaccinated to prevent transmission to pregnant women and reduce the risk of congenital CMV infection [9]. Our results suggest that infants of Pakistani origin would need to be vaccinated before age one and the impact of vaccinating children with recent natural infection needs to be explored.

\section{Additional files}

Additional file 1: Further details of Methods; text giving further details of the Methods including sample size calculations. (DOCX $12 \mathrm{~kb}$ )

Additional file 2: Total hours of informal and formal childcare by ethnic group; table showing categories of total hours of informal and formal childcare by ethnic group. (DOCX $13 \mathrm{~kb}$ )

Additional file 3: $C M V$, EBV and VZV incidence data for Figure 2; table showing the CMV, EBV and VZV incidence data presented in Figure 2. (DOCX $13 \mathrm{~kb})$

\section{Abbreviations}

ALL IN: Allergy and Infection Study; BiB: Born in Bradford; Cl: Confidence interval; CMV: Cytomegalovirus; DNA: Deoxyribonucleic acid; EBV: Epstein Barr virus; IgG: Immunoglobulin G; OR: Odds ratio; VZV: Varicella-zoster virus

\section{Acknowledgements}

Born in Bradford is only possible because of the enthusiasm and commitment of the Children and Parents in BiB. We are grateful to all the participants, health professionals and researchers who have made Born in Bradford happen. We would like to thank Andy Hall (previously at LSHTM, now retired) for his work on ALL IN, Pauline Raynor (former BiB Programme Manager) for her work in helping set up ALL IN, the BiB Community Research Administrators who carried out the ALL IN visits, Desmond Maranao and Kinjal Kadakia (Royal Free) for running the lgG assays and Emily Webb (LSHTM) for statistical advice. 


\section{Funding}

This work was supported by the Wellcome Trust (grant numbers: 083521/Z/ 07/Z, 083521/Z/07/A). Funding also provided by the National Institute for Health Research (NIHR) under its Collaboration for Applied Health Research and Care (CLAHRC) for Yorkshire and Humber.

\section{Availability of data and materials}

The datasets used and/or analysed during the current study are available from the corresponding author on reasonable request.

\section{Authors' contributions}

LP conceived and designed the study, analysed and interpreted the data and drafted and revised the manuscript. DW co-ordinated data collection, interpreted the data and revised the manuscript. PG designed the study, interpreted the data and revised the manuscript. MP analysed the laboratory data and drafted some of the manuscript. RA co-ordinated the processing, storage and transport of laboratory samples and revised the manuscript. JW designed the study, interpreted the data and revised the manuscript. All authors have given final approval of the version to be published.

\section{Competing interests}

PG's institution has received grants from Sanofi Pasteur and Genentech/Roche, but he has no personal conflicts to declare. LP, DW, MP, RA, JW declare that they have no competing interests.

\section{Consent for publication}

Not applicable

\section{Ethics approval and consent to participate}

This study had ethical approval from the London School of Hygiene \& Tropical Medicine ethics committee (ref: 5320) and the Bradford Research Ethics committee (ref: 08/H1302/21). Parents (usually the mother) gave informed, written consent to take part in the study.

\section{Publisher's Note}

Springer Nature remains neutral with regard to jurisdictional claims in published maps and institutional affiliations.

\section{Author details}

${ }^{1}$ Department of Medical Statistics, London School of Hygiene and Tropical Medicine, Keppel Street, London WC1E 7HT, UK. ${ }^{2}$ Bradford Institute for Health Research, Bradford, UK. ${ }^{3}$ Centre for Virology, University College London Medical School, London, UK. ${ }^{4}$ Virology Department, Royal Free Hospital London, UK. ${ }^{5}$ Department of Biochemistry, Bradford Royal Infirmary, Bradford, UK.

Received: 7 December 2016 Accepted: 10 March 2017

Published online: 21 March 2017

\section{References}

1. Miles DJ, van der Sande M, Jeffries D, Kaye S, Ojuola O, Sanneh M, Cox M, Palmero MS, Touray ES, Waight $P$, et al. Maintenance of large subpopulations of differentiated CD8 T-cells two years after cytomegalovirus infection in Gambian infants. PLoS One. 2008:3(8):e2905

2. Holder B, Miles DJ, Kaye S, Crozier S, Mohammed NI, Duah NO, Roberts E, Ojuola O, Palmero MS, Touray ES, et al. Epstein-Barr virus but not cytomegalovirus is associated with reduced vaccine antibody responses in Gambian infants. PLoS One. 2010;5(11):e14013.

3. Leray E, Moreau T, Fromont A, Edan G, Epidemiology of multiple sclerosis. Rev Neurol. 2016;172(1):3-13.

4. Cohen II, Fauci AS, Varmus H, Nabel GJ. Epstein-Barr virus: an important vaccine target for cancer prevention. Sci Transl Med. 2011;3(107):107fs.

5. Simanek AM, Dowd JB, Pawelec G, Melzer D, Dutta A, Aiello AE. Seropositivity to cytomegalovirus, inflammation, all-cause and cardiovascular disease-related mortality in the United States. PLoS One. 2011;6(2):e16103.

6. Pawelec G, Derhovanessian E. Role of CMV in immune senescence. Virus Res. 2011;157(2):175-9.

7. Purssell E. Shingles vaccination: background and advice for community nurses Br J Community Nurs. 2014;19(9):442-6.

8. Kharfan-Dabaja MA, Boeckh M, Wilck MB, Langston AA, Chu AH, Wloch MK Guterwill DF, Smith LR, Rolland AP, Kenney RT. A novel therapeutic cytomegalovirus DNA vaccine in allogeneic haemopoietic stem-cell transplantation: a randomised, double-blind, placebo-controlled, phase 2 trial. Lancet Infect Dis. 2012;12(4):290-9.

9. Griffiths PD. Burden of disease associated with human cytomegalovirus and prospects for elimination by universal immunisation. Lancet Infect Dis. 2012;12(10):790-8.

10. Cohen Jl. Epstein-barr virus vaccines. Clin Translational Immunol. 2015;4(1):e32.

11. Lanzieri TM, Kruszon-Moran D, Amin MM, Bialek SR, Cannon MJ, Carroll MD, Dollard SC. Seroprevalence of cytomegalovirus among children 1 to 5 years of age in the United States from the National Health and Nutrition Examination Survey of 2011 to 2012. Clin Vaccine Immunol. 2015;22(2):245-7.

12. Wright J, Small N, Raynor P, Tuffnell D, Bhopal R, Cameron N, Fairley L, Lawlor DA, Parslow R, Petherick ES, et al. Cohort Profile: The Born in Bradford multi-ethnic family cohort study. Int J Epidemiol. 2013;42(4):978-91.

13. Pembrey L, Raynor P, Griffiths P, Chaytor S, Wright J, Hall AJ. Seroprevalence of cytomegalovirus, Epstein Barr virus and varicella zoster virus among pregnant women in Bradford: a cohort study. PLoS One. 2013:8(11):e81881.

14. Walter S, Atkinson C, Sharland M, Rice P, Raglan E, Emery VC, Griffiths PD. Congenital cytomegalovirus: association between dried blood spot viral load and hearing loss. Arch Dis Child Fetal Neonatal Ed. 2008;93(4):F280-285.

15. Strachan DP. Family size, infection and atopy: the first decade of the "hygiene hypothesis". Thorax. 2000;55 Suppl 1:S2-10.

16. Peckham CS, Johnson C, Ades A, Pearl K, Chin KS. Early acquisition of cytomegalovirus infection. Arch Dis Child. 1987;62(8):780-5.

17. Schleiss MR. Acquisition of human cytomegalovirus infection in infants via breast milk: natural immunization or cause for concern? Rev Med Virol. 2006;16(2):73-82.

18. Manikkavasagan G, Dezateux C, Wade A, Bedford $\mathrm{H}$. The epidemiology of chickenpox in UK 5-year olds: an analysis to inform vaccine policy. Vaccine. 2010;28(48):7699-705.

19. Ma X, Buffler PA, Selvin S, Matthay KK, Wiencke JK, Wiemels JL, Reynolds P Daycare attendance and risk of childhood acute lymphoblastic leukaemia. Br J Cancer. 2002;86(9):1419-24.

20. Harding NJ, Birch JM, Hepworth SJ, McKinney PA. Infectious exposure in the first year of life and risk of central nervous system tumors in children: analysis of day care, social contact, and overcrowding. Cancer Causes Control. 2009;20(2):129-36.

21. Crowcroft NS, Vyse A, Brown DW, Strachan DP. Epidemiology of Epstein-Barr virus infection in pre-adolescent children: application of a new salivary method in Edinburgh, Scotland. J Epidemiol Community Health. 1998;52(2):101-4.

22. Balfour Jr HH, Sifakis F, Sliman JA, Knight JA, Schmeling DO, Thomas W. Age-specific prevalence of Epstein-Barr virus infection among individuals aged 6-19 years in the United States and factors affecting its acquisition. J Infect Dis. 2013;208(8):1286-93.

23. StataCorp. Stata Statistical Software: Release 13. College Station: StataCorp LP; 2013.

24. Vyse AJ, Gay NJ, Hesketh LM, Morgan-Capner P, Miller E. Seroprevalence of antibody to varicella zoster virus in England and Wales in children and young adults. Epidemiol Infect. 2004;132(6):1129-34.

25. Talukder YS, Kafatos G, Pinot de Moira A, Aquilina J, Parker SP, Crowcroft NS, Brown DW, Breuer J. The seroepidemiology of varicella zoster virus among pregnant Bangladeshi and white British women in the London Borough of Tower Hamlets, UK. Epidemiol Infect. 2007:135(8):1344-53.

26. Sinha DP. Chickenpox-a disease predominantly affecting adults in rural West Bengal, India. Int J Epidemiol. 1976;5(4):367-74.

27. Korndewal MJ, Mollema L, Tcherniaeva I, van der Klis F, Kroes AC, Oudesluys-Murphy AM, Vossen AC, de Melker HE. Cytomegalovirus infection in the Netherlands: seroprevalence, risk factors, and implications. J Clin Virol. 2015;63:53-8.

28. Seale H, Maclntyre CR, Gidding HF, Backhouse JL, Dwyer DE, Gilbert L. National serosurvey of cytomegalovirus in Australia. Clin Vaccine Immunol. 2006;13(11):1181-4.

29. Nilsson C, Linde A, Montgomery SM, Gustafsson L, Nasman P, Blomberg MT, Lilja G. Does early EBV infection protect against IgE sensitization? J Allergy Clin Immunol. 2005;116(2):438-44.

30. Dowd JB, Zajacova A, Aiello A. Early origins of health disparities: burden of infection, health, and socioeconomic status in U.S. children. Soc Sci Med. 2009:68(4):699-707.

31. O'Brien TP, Thompson JM, Black PN, Becroft DM, Clark PM, Robinson E, Wild C, Mitchell EA. Prevalence and determinants of cytomegalovirus infection in pre-school children. J Paediatr Child Health. 2009;45(5):291-6. 
32. Jansen MA, van den Heuvel D, Bouthoorn SH, Jaddoe WW, Hooijkaas $H$, Raat H, Fraaij PL, van Zelm MC, Moll HA: Determinants of Ethnic Differences in Cytomegalovirus, Epstein-Barr Virus, and Herpes Simplex Virus Type 1 Seroprevalence in Childhood. J Pediatrics. 2016;170:126-34.

33. Bernsen RM, Nagelkerke NJ, al-Ramadi BK. Does paternal antigen-induced secretion of interleukin-10 by T regulatory cells mediate the birth order effect? Med Hypotheses. 2006;67(4):740-3.

34. Griffiths PD, Stanton A, McCarrell E, Smith C, Osman M, Harber M, Davenport A, Jones $\mathrm{G}$, Wheeler DC, O'Beirne J, et al. Cytomegalovirus glycoprotein-B vaccine with MF59 adjuvant in transplant recipients: a phase 2 randomised placebocontrolled trial. Lancet. 2011;377(9773):1256-63.

35. Sabbaj S, Pass RF, Goepfert PA, Pichon S. Glycoprotein B vaccine is capable of boosting both antibody and CD4 T-cell responses to cytomegalovirus in chronically infected women. J Infect Dis. 2011;203(11):1534-41.

36. Gibbs S, Surridge H, Adamson R, Cohen B, Bentham G, Reading R. Atopic dermatitis and the hygiene hypothesis: a case-control study. Int J Epidemiol. 2004;33(1):199-207.

37. Morris MC, Edmunds WJ, Hesketh LM, Vyse AJ, Miller E, Morgan-Capner P, Brown DW. Sero-epidemiological patterns of Epstein-Barr and herpes simplex (HSV-1 and HSV-2) viruses in England and Wales. J Med Virol. 2002;67(4):522-7.

38. Khandaker GM, Stochl J, Zammit S, Lewis G, Jones PB. Childhood EpsteinBarr Virus infection and subsequent risk of psychotic experiences in adolescence: a population-based prospective serological study. Schizophr Res. 2014;158(1-3):19-24.

39. Condon LM, Cederberg LE, Rabinovitch MD, Liebo RV, Go JC, Delaney AS, Schmeling DO, Thomas W, Balfour Jr HH. Age-specific prevalence of Epstein-Barr virus infection among Minnesota children: effects of race/ ethnicity and family environment. Clin Infect Dis. 2014;59(4):501-8.

40. Goodier MR, White MJ, Darboe A, Nielsen CM, Goncalves A, Bottomley C, Moore SE, Riley EM. Rapid NK cell differentiation in a population with near-universal human cytomegalovirus infection is attenuated by NKG2C deletions. Blood. 2014;124(14):2213-22.

41. Rostgaard K, Wohlfahrt J, Hjalgrim H. A genetic basis for infectious mononucleosis: evidence from a family study of hospitalized cases in Denmark. Clin Infect Dis. 2014;58(12):1684-9.

42. Sidorchuk A, Wickman M, Pershagen G, Lagarde F, Linde A. Cytomegalovirus infection and development of allergic diseases in early childhood: interaction with EBV infection? J Allergy Clin Immunol. 2004;114(6):1434-40.

43. Saghafian-Hedengren S, Sverremark-Ekstrom E, Linde A, Lilja G, Nilsson C. Early-life EBV infection protects against persistent IgE sensitization. J Allergy Clin Immunol. 2010;125(2):433-8.

\section{Submit your next manuscript to BioMed Central and we will help you at every step:}

- We accept pre-submission inquiries

- Our selector tool helps you to find the most relevant journal

- We provide round the clock customer support

- Convenient online submission

- Thorough peer review

- Inclusion in PubMed and all major indexing services

- Maximum visibility for your research

Submit your manuscript at www.biomedcentral.com/submit
Biomed Central 